This is a pre-copy-editing, author produced PDF of an article accepted for publication in Medicine \& Science in Sporta \& Exercise following peer review. The definitive publisher-authenticated version - Easton, Chris, Merkett, Dylan, Stock, Chelsea and Grace, Fergal (2011) The effects of dietary nitrate supplementation on time trial performance in trained cyclists., Medicine \& Science in Sports \& Exercise, 2011, 43 (Supplement 1 5), S.593.is available online at http://journals.lww.com/acsm-msse/Fulltext/2011/05001/ The_Effects_of_Dietary_Nitrate_Supplementation_on.2444.aspx 


\section{The Effects of Dietary Nitrate Supplementation on Time Trial Performance in Trained Cyclists.}

C.Easton ${ }^{1}$, D.Merkett ${ }^{1}$, C.Stock ${ }^{1}$, F.Grace $^{2}$.

${ }^{1}$ Kingston University, Kingston upon Thames, England, ${ }^{2}$ University of the West of Scotland, Hamilton, Scotland.

Supplementation with nitrate-rich beetroot juice $(\mathrm{BR})$ has been reported to lower resting blood pressure, reduce the oxygen cost $\left(\mathrm{VO}_{2}\right)$ of exercise and extend time to exhaustion during high-intensity steady state exercise (Bailey et al. J Appl Physiol 107: 1144-55). However, no study to date has investigated the effects of nitrate supplementation on selfpaced exercise performance. PURPOSE: To determine the effects of BR supplementation on $16 \mathrm{~km}$ time trial performance in trained cyclists. METHODS: Eight male cyclists completed an exercise test to determine their ventilatory threshold $\left(\mathrm{V}_{\mathrm{T}}\right)$ before receiving either $500 \mathrm{ml} \cdot$ day $^{-1}$ of BR or $500 \mathrm{ml} \cdot$ day $^{-1}$ of placebo (PL: blackcurrant cordial and water) for six consecutive days in a single-blind, randomised cross-over design. Subsequently, each participant completed 30 min of steady state cycling at $80 \% \mathrm{~V}_{\mathrm{T}}$ followed immediately by a 16 $\mathrm{km}$ time trial. Respiratory variables, heart rate, blood [lactate] and [glucose] were collected at 5 min intervals during the steady state exercise. RESULTS: There were no differences in heart rate $(p=0.19)$, [lactate] $(p=0.21)$ or [glucose] $(p=0.28)$ between conditions. $\mathrm{VO}_{2}$ was significantly lower during the steady state exercise in the BR condition $(2.2 \pm 0.2 \mathrm{~L} / \mathrm{min})$ compared to the PL condition $(2.4 \pm 0.2 \mathrm{~L} / \mathrm{min}, p=0.04)$. The time to complete the $16 \mathrm{~km}$ time trial was not different between experimental conditions (BR: $26.1 \pm 2.2 \mathrm{~min}$ vs. PL: 25.8 $\pm 1.9 \mathrm{~min}, p=0.34)$. CONCLUSIONS: Consistent with previous research, dietary nitrate supplementation in the form of $\mathrm{BR}$ resulted in a significant reduction in $\mathrm{VO}_{2}$ during steady state exercise. However, BR did not enhance self paced exercise performance in trained cyclists. Further research is required to identify the physiological mechanism underlying the action of dietary nitrate supplementation on exercise performance. 